Hydrology and Earth System Sciences, 4(2), 239-249 (2000) (C) EGS

\title{
Modelling catchment hydrology within a GIS based SVAT-model framework
}

\author{
R. Ludwig and W. Mauser \\ Institute of Geography, University of Munich, Department of Geography and Geographical Remote Sensing, Luisenstrasse 37, \\ 80333 Munich, Germany \\ e-mail for corresponding author: r.ludwig@iggf.geo.uni-muenchen.de
}

\begin{abstract}
The physically-based soil-vegetation-atmosphere-transfer model PROMET (PRocess-Oriented Model for Evapo Transpiration) developed at the Institute of Geography, University of Munich, is applied to the Ammer basin (approx. $600 \mathrm{~km}^{2}$ ) in the alpine foreland of Germany. The hourly actual evapotranspiration rate is calculated for a 14-year time series. A rainfall-runoff model, based on an enhanced distributed TOPMODEL structure, is linked to the SVAT-model in order to provide a hydrological model covering the water-cycle at the basin scale in a $30 \mathrm{~m}$-resolution. The model is driven with meteorological data taken from regular synoptic stations of the German Weather Service. Soil physical and plant physiological parameters for the SVAT model were either measured at the test site or taken from literature. The topographical parameters were derived from detailed digital terrain analysis. The study intends to combine, within a GIS-based model framework, the understanding and application of physical processes inherent in the basin such as the spatial distribution and temporal evolution of evapotranspiration and runoff patterns. The influence of an evapotranspiration coefficient $E T_{\text {coeff; }}$ implemented in the formulation of the soil-topographic-index, to account for seasonal dynamics in distributed runoff formation due to the annual course of vegetation activity is investigated. The SVAT model shows convincing results in the long-term water balance description with a mean annual deviation of less then $6 \%$ over a fourteen year time period. Introducing the evapotranspiration-soil-topographic-index $\alpha_{E T}$ leads to a considerable improvement; the runoff model component simulating the daily runoff over the year reaches an efficiency of $\varepsilon=0.92$.
\end{abstract}

Keywords: Water cycle; Geographic Information System; SVAT; TOPMODEL

\section{Introduction}

The estimation of the spatial and temporal distribution of natural water resources plays a key role in hydrological research. Many models have been developed to simulate the dynamics of hydrological systems. These models need to be supplied with a reasonable but minimum amount of physiogeographical data at a reasonably high spatial and temporal resolution, employing different degrees of accuracy in physical process description. The development in Geographical Information Systems (Bonham-Carter, 1994) enables the digital description of spatial and temporal catchment characteristics pertinent to hydrological modelling (Moore et al., 1993; Kovar and Nachtnebel, 1996). In this study, a GIS-structured, four dimensional database of static and dynamic components is provided to meet the requirements of distributed modelling of the water-cycle. Actual evapotranspiration is a key balance term in the hydrological cycle, being the decisive limiting factor for river runoff and groundwater recharge. It is a spatially heterogeneous process depending on a large variety of influencing factors, such as climate, vegetation and soil, which have to be taken into account. To improve the understanding and the simulation of the processes involved, detailed physicallybased and distributed models, such as the Systeme Hydrologique European SHE (Abbott et al., 1986), or Soil-Vegetation-Atmosphere-Transfer (SVAT) schemes, such as the AMBETI (Braden, 1995), have been developed. In this study, the PRocess-Oriented Model for Evapo Transpiration PROMET (Mauser and Schädlich, 1998) is applied; this calculates the actual evapotranspiration rates of heterogenous plant stands over the year. The structure of PROMET and its outputs are combined with an extended version of the conceptual rainfall-runoff model TOPMODEL (TOPopraphic MODEL, Beven et al, 1995), to calculate the spatial and temporal distribution of runoff formation and concentration for a one-year period in the Ammer Catchment. Numerous applications and model developments have emerged from the conceptual TOPMODEL approach (Beven, 1997). They investigate and emphasize very different aspects, such as sensitivity analysis (Franchini et al., 1996; Bruneau et al., 1995), 
distributed input data (Saulnier et al., 1998), validation methods (Seibert, 1999) and uncertainty (Beven, 1993) and lead to a wide international distribution of the model concept. Similar links of detailed physical model descriptions and the TOPMODEL concept have been performed by Famiglietti and Wood (1994), Watson et al. (1996) or Schulla (1997). Most existing models use quasi-three dimensional descriptions with approximate solutions on a variety of spatial discretizations (Romanowicz et al., 1993). The vast development in computer power counteracts the increased computational effort of distributed modelling and allows a reasonable performance of the model in use. For the wider application of complex models, it is also necessary to create an interface providing extensive automation of data management and processing, for which again GIS-techniques can be exploited.

\section{The study area}

The Ammer catchment is located approximately $60 \mathrm{~km}$ southwest of Munich in the Bavarian alpine forelands and covers an area of about $600 \mathrm{~km}^{2}$. In its southern part, it reaches the mountainous regions of the Bavarian Alps with altitudes up to almost $2000 \mathrm{~m}$ above sea level. From the steep slopes of the mountains, the Ammer river heads north through the smooth relief molassic structures of the alpine foreland, before it flows into Lake Ammer $(533 \mathrm{~m}$ asl). About $50 \%$ of the catchment is forested, while the rest is mainly in agricultural use ( $90 \%$ pasture, $10 \% \mathrm{crop})$. The mean annual amount of precipitation is $1200 \mathrm{~mm}$, ranging from $900 \mathrm{~mm}$ in the north to over $1800 \mathrm{~mm}$ in the mountains.

\section{The SVAT model PROMET}

The physically based soil-vegetation-atmosphere-transfer model PROMET (PRocess-Oriented Model for EvapoTranspiration) developed at the Institute of Geography, University of Munich (Mauser and Schädlich, 1998), is based on the Penman-Monteith equation, which calculates the actual evapotranspiration as a function of water availability, radiation balance and the physiological regulation mechanisms of heterogeneous plant stands. The model consists of a number of interdependent components delivering the necessary inputs for the Penman-Monteith equation (Eqn. 4):

- a one dimensional soil water module for the modelling of the soil water content, as a function of infiltration, exfiltration and capillary rise applying a simplified solution of the Richards equation (Eagleson, 1978). For homogeneous soils, the change in soil moisture $\theta$ is calculated using the one-dimensional Philip equation, with time $t$, soil depth $z$, hydraulic conductivity $K$ and diffusivity $D$, written as:

$$
\frac{\delta \Theta}{\delta t}=\frac{\delta}{\delta z}\left[D(\Theta) \frac{\delta \Theta}{\delta z}\right]-\frac{\delta K(\Theta)}{\delta z}
$$

- a plant module, modelling the water transport in the plant controlled by its stomatal resistance $r_{s}$. This is determined as a function of intercepted photosynthetic active radiation $P A R$ (Eqn. 2). Temperature, humidity and soil moisture, represented by an environment influence function $g$, are introduced as limiting factors for $r_{s}$ (Baldocchi et al. 1987), with $r_{s \min }$ being the plant specific minimum stomatal resistance and $b$ a plant specific parameter

$$
r_{s}(P A R)=\left(r_{s \min }+\left(b(P A R) \cdot r_{s \min }\right) / P A R\right) / g
$$

- an aerodynamic component modelling the removal of transpired water vapour into the atmosphere (Monteith, 1965). The fraction of shaded to sunlit leaf area is calculated by a 10-layer radiative transfer model (Norman, 1979) in order to scale leaf stomatal resistance to canopy resistance. Plant height and albedo, taken from measurements and literature, are used to calculate the aerodynamical resistance $r_{a}$, with $u(z)$ being the wind speed in altitude $z$, the Karman constant $k(=0.41)$, roughness length $z_{0}$ and the displacement height $d$

$$
r_{a}=\frac{1}{k^{2} \cdot u(z)} \cdot \ln ^{2}\left(\frac{z-d}{z_{0}}\right)
$$

- a one-layer snow module describing the accumulation and melt processes and calculating the melt water runoff according to energy balance terms (Todini, 1996)

The kernel model of PROMET handles the modelling of the actual evapotranspiration based on the scale-independent Penman-Monteith equation (Eqn. 4), while the spatial data modeller exploits the capabilities of GIS-techniques to prepare the input data according to the application scale.

$$
E_{v}=\frac{\Delta \cdot(Q-B)+\rho \cdot c_{p} \cdot \frac{\left(E_{L}-e_{L}\right)}{r_{a}}}{\Delta+\gamma \cdot \frac{1+r_{s}}{r_{a}}}
$$

with $\Delta=$ slope of the water vapour pressure curve $v$. temperature; $\gamma=$ psychrometric constant; $Q=$ radiation balance; $B=$ soil heat flux; $\rho=$ density of air; $c_{p}=$ specific heat of air at constant pressure; $E_{L}=$ saturated water vapour pressure at gauging level; $e_{L}=$ current water vapour pressure at gauging level; $r_{a}=$ aerodynamical resistance and $r_{s}=$ plant resistance.

The maximum thickness of the intercepted water layer $I_{\max }$ by the plant canopy depends on its leaf area index ( $L A I)$ and is calculated as proposed by von HoynigenHuene (Eqn. 5, 1983). Evapotranspiration from the 
Table 1. Water balance for the Ammer basin as calculated by PROMET for a 14-year time series.

\begin{tabular}{|c|c|c|c|c|c|}
\hline Year & $\begin{array}{l}P \\
(\mathrm{~mm})\end{array}$ & $\begin{array}{l}\text { ET } \\
(\mathrm{mm})\end{array}$ & $\begin{array}{l}\text { P-ET } \\
(\mathrm{mm})\end{array}$ & $\begin{array}{l}\text { Runoff } \\
(\mathrm{mm})\end{array}$ & $\begin{array}{l}\text { Absolute } \\
\text { Deviation } \\
(\%)\end{array}$ \\
\hline 1984 & 1094,7 & 495,9 & 598,8 & 539,2 & 11,1 \\
\hline 1985 & 1157,4 & 555,1 & 602,3 & 575,0 & 4,7 \\
\hline 1986 & 1226,3 & 531,2 & 695,0 & 667,2 & 4,2 \\
\hline 1987 & 1190,2 & 503,1 & 687,1 & 654,8 & 4,9 \\
\hline 1988 & 1279,6 & 557,3 & 722,3 & 688,8 & 4,8 \\
\hline 1989 & 1249,2 & 523,2 & 726,0 & 660,2 & 9,9 \\
\hline 1990 & 1375,0 & 578,3 & 796,7 & 745,5 & 6,8 \\
\hline 1991 & 1022,3 & 514,9 & 507,4 & 547,4 & 7,3 \\
\hline 1992 & 1080,6 & 574,5 & 506,1 & 515,7 & 1,8 \\
\hline 1993 & 1491,4 & 536,2 & 955,2 & 859,8 & 11,1 \\
\hline 1994 & 1143,3 & 593,9 & 549,4 & 543,3 & 1,1 \\
\hline 1995 & 1371,3 & 492,9 & 878,4 & 777,4 & 13,0 \\
\hline 1996 & 1300,2 & 513,6 & 786,6 & 751,6 & 4,7 \\
\hline 1997 & 1092,9 & 499,3 & 593,6 & 580,8 & 2,2 \\
\hline Mean & 1219,6 & 533,5 & 686,1 & 650,5 & \\
\hline \multicolumn{5}{|c|}{ Mean annual deviation } & 6,2 \\
\hline \multicolumn{5}{|c|}{ 14-year deviation } & $+5,47$ \\
\hline
\end{tabular}

interception storage is assumed to occur at the potential rate.

$$
I_{\max }=0.935+0.498 \cdot L A I-0.00575 \cdot L A I^{2}
$$

Until now PROMET does not consider lateral flow between elements; therefore evapotranspiration loss may be overestimated on slopes and underestimated on wet valley bottoms. This problem is addressed in current programme development. PROMET has been applied to the Ammer catchment over a 14-year period from 1984-1997, computing the hourly actual evapotranspiration on a $30 \mathrm{~m}$ grid. For this purpose, the gauged precipitation data are corrected individually to account for the typical recording losses due to the influence of wind turbulence, evapotranspiration and moistening, employing a temperature and wind speed dependent method (Schulla, 1997). Inserting the modelled evapotranspiration into the water balance equation, and comparing the resulting runoff term with the gauged runoff at the catchment outlet shows a mean annual deviation of $6.2 \%$ (Table 1 ).

For further analysis, the hydrological year 1992 is selected, since accurate land use information is available from Landsat TM imagery. The deviation in runoff volume for this period is only $-1.8 \%$ (Fig. 1 ).

However, this information supplies only theoretical runoff availability and gives no further information on the actual temporal and spatial distribution of runoff formation and concentration.

To close the water cycle, the meteorological input and evapotranspiration output of PROMET is used to drive an enhanced version of TOPMODEL (Beven and Kirkby, 1979). The enhancement, which considers the annual course of vegetation development in terms of evapotranspiration, has been developed by the authors. The GIS structure of PROMET enables distributed processing of the required input data for the runoff model. For the purpose of distributed modelling, the spatial pattern of evapotranspiration is evaluated accurately. Remotely sensed thermal data offer an opportunity to validate the PROMET output, due to the correlation of evapotranspiration with

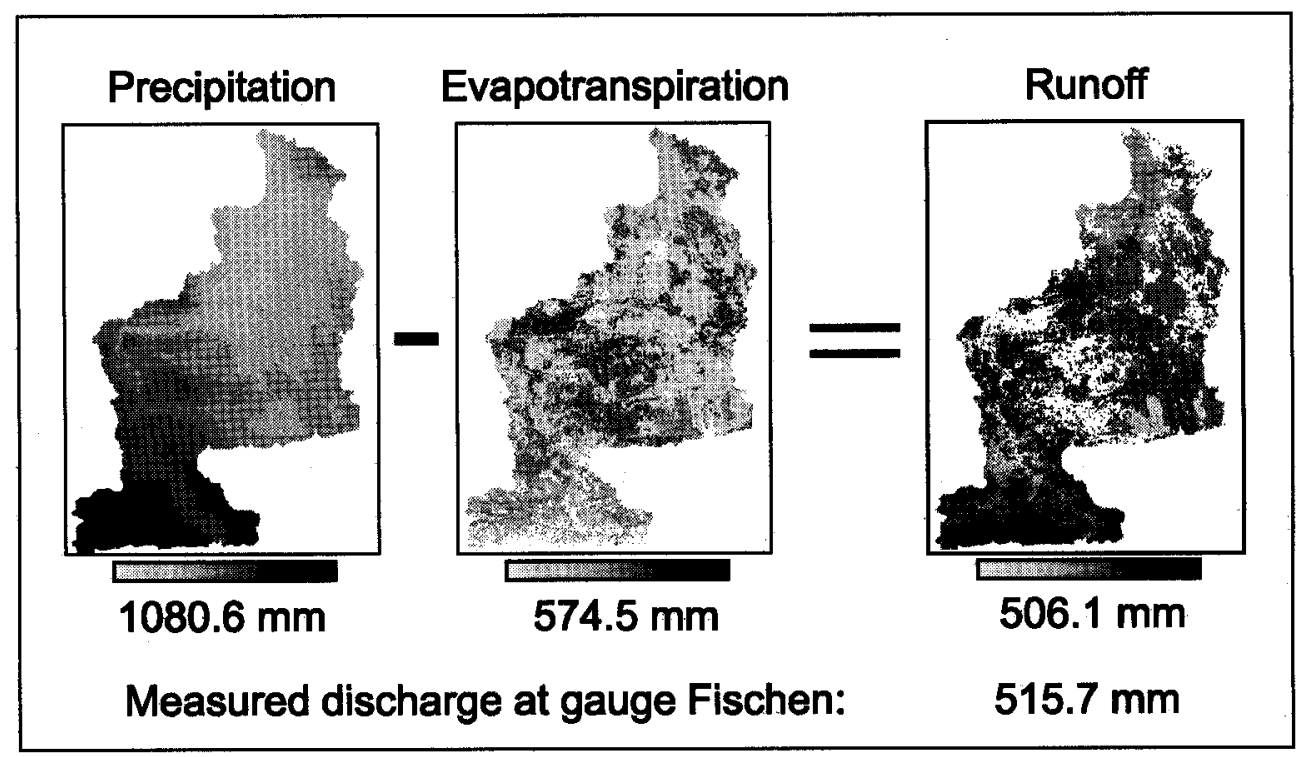

Fig. 1. PROMET modelled water balance for the Ammer catchment (hydrological year 1992). 


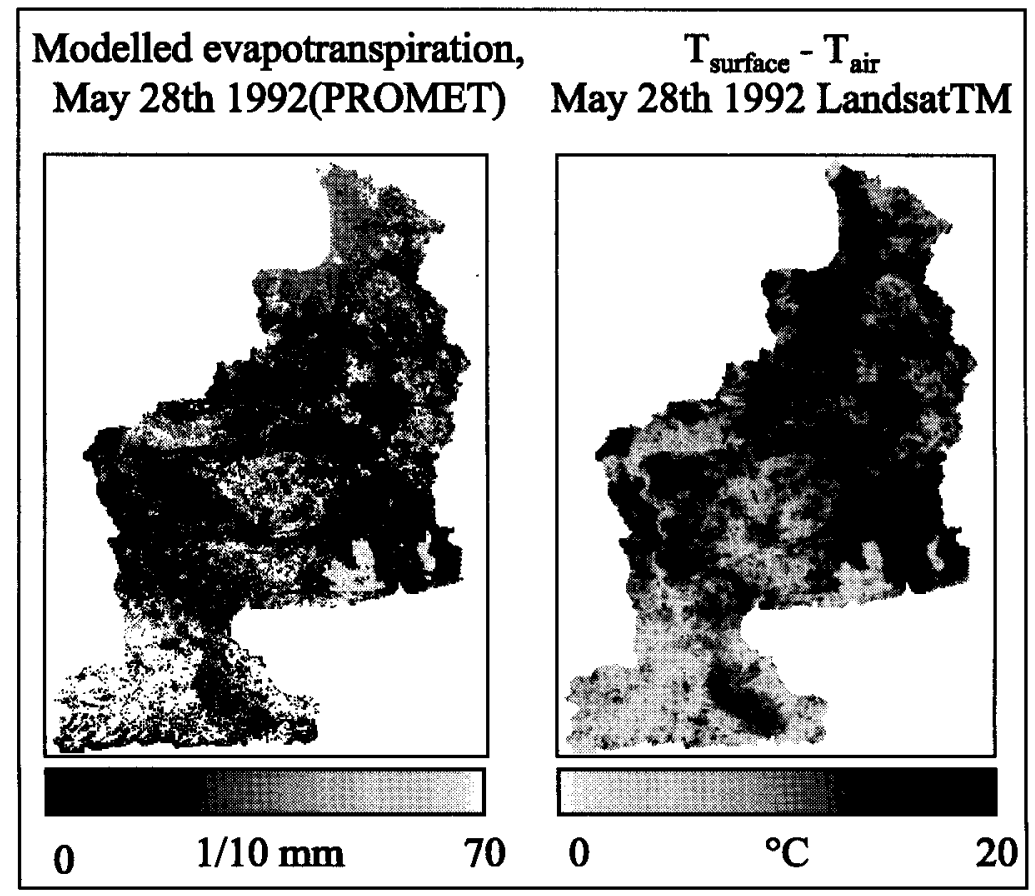

Fig. 2. Validation of the evapotranspiration pattern modelled by PROMET in the Ammer catchment using Landsat TM surface temperature and ground measured temperature data.

surface temperature. As a first step, neglecting a variety of other important parameters such as surface and aerodynamic resistance (Lu Zhang, 1995), the surface temperature ( $T_{\text {surface}}$ ) taken from the thermal band of the Landsat TM image of May $28^{\text {th }} 1992$ minus the measured air temperature $\left(T_{\text {air }}\right)$ is compared (Fig. 2). For the correlation, the coefficient of determination of $\mathrm{r}^{2}=0.51$ with the modelled evapotranspiration pattern.

\section{The Geographical Information System}

The four-dimensional, geographical database built for this application contains a static and a dynamic component. The static component consists of the topographical information derived from the digital terrain model MilGeo (resolution of $1 \mathrm{arc} \mathrm{s}, 1 \mathrm{~m}$ in altitude), a land use classification of a Landsat TM image (May 28 $8^{\text {th }} 1992,30 \mathrm{~m}$ resolution) using the knowledge-based fuzzy-logic technique (Stolz and Mauser, 1996) and a digital soil map ( $30 \mathrm{~m}$ resolution), linked to various tables containing the soil specific Brooks-Corey parameters (Brooks and Corey, 1964). The land use is coupled with tables describing the temporal development of plant height, leaf area index and albedo for each land use class.

The dynamic component of the GIS stores all meteorological parameter fields, which vary quickly in time and space and have to be updated for each calculation timestep (Fig. 3).
The meteorological data are taken from regular synoptic stations of the German Weather Service at a 7-hour temporal resolution. The station data is spatially and temporally interpolated ( $30 \mathrm{~m}$ grid, 1-hour resolution). For the meteorological parameters temperature, humidity, cloudiness, from which global radiation is derived by an approximation (Möser and Raschke, 1983) and wind speed the temporal interpolation employs a cubic spline between measurements. Particularly for precipitation however, it distinguishes short events (single recording), for which a Gaussian distribution is assumed, and long term events (at least two consecutive recordings) for which the measured precipitation is equally distributed in time. For the spatial interpolation, the measured station values undergo a trend analysis with elevation. The residuals from trend analysis are then interpolated using a cubic inverse distance approach. The interpolated residuals are then added to the trend level. For these procedures, 12 gauging stations, symmetrically distributed in and around the Ammer catchment (in location and altitude) were available.

To derive topographically relevant model parameters, such as the distribution of the topographic index, the delineation of subcatchments and river networks and the calculation of hydraulic lengths and slopes, an analysis of the digital terrain model was conducted. Using the program package TOPAZ (Garbrecht and Martz, 1995). It performs an analysis based on the critical source area concept (CSA), by interactively defining a distributed threshold of upslope area for the development of a river and accounting for possible heterogeneities in geology, pedology or land use. 


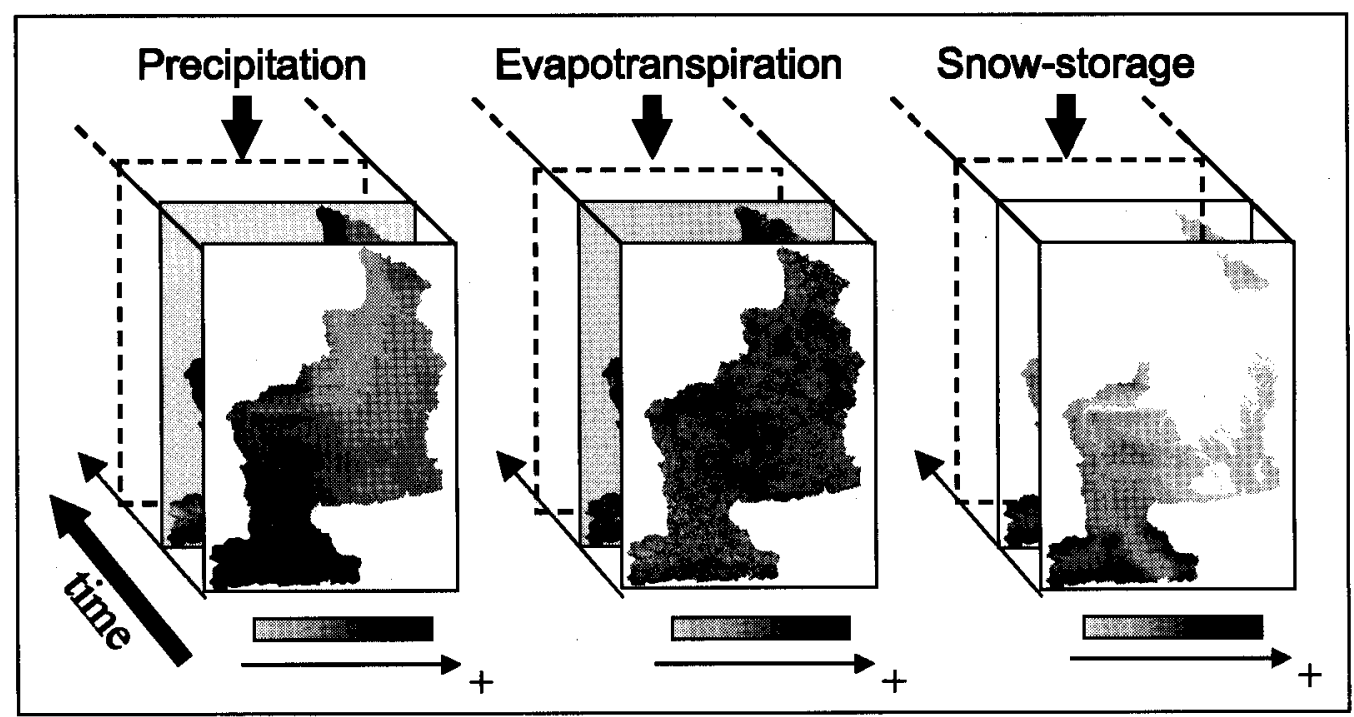

Fig. 3. Dynamic components of the Geographical Information System.

The flow direction for every raster element is unidirectionally defined according to the steepest slope. After pre-processing of the elevation data, in which all sinks and dam structures are removed, the delineation of the channel network is performed. A subcatchment is then assigned to each of the channel sections (Garbrecht and Martz, 1995). Supplementary information, such as channel length and slope or hydraulic length and mean slope of subcatchments as well as the routing-sequence through all catchments, is stored in tabular format and can be accessed directly by the runoff model. The following datasets are provided for the runoff component as fully distributed raster images in a GIS-structure

- soil information containing the values of the soil specific Brooks-Corey parameters (saturated hydraulic conductivity $\mathrm{K}_{\mathrm{s}}$, pore size distribution index, bubbling capillary pressure, porosity etc.)

- spatially distributed root zone storages derived from soil-specific field capacity and plant-specific rooting depth

- hourly or daily actual evapotranspiration rates as calculated by PROMET

- temporally and spatially interpolated hourly or daily precipitation and snow cover/snowmelt rates derived from the synoptic data of the German Weather Service - subcatchment structure and river network along with the corresponding topographic parameters derived from the digital terrain analysis

Furthermore, the necessary information for the computation of surface runoff concentration by time-delay histograms is supplied, such as catchment size, hydraulic length and channel slope and length. The digital terrain analysis led to the distinction of 52 subcatchments within the Ammer basin, for which the water-balance and the resulting hydrographs are calculated individually.

\section{The extended TOPMODEL}

In this study, an extended version of the original TOPMODEL is presented, taking advantage of the raster GIS-structure provided by PROMET. Many assertions are based on the adoption of so-called hydrologically similar units, in which model calculations are performed for classes believed to have hydrological similarity through belonging to a specific class of the topographic index. In the work presented here, by contrast, the local water-balance is computed for each pixel in the catchment. It is assumed that the consideration of distributed soil and land use information as well as spatial rainfall patterns (Obled et al., 1994) is indispensible to understanding the physical processes involved in runoff formation and hence for accurate hydrological modelling. Nevertheless, three basic assumptions underpinning the TOPMODEL structure (Beven $e t$ al., 1995; Franchini et al., 1996) need to be held:

- the dynamics of the saturated zone are approximated by successive steady states

- the hydraulic gradient of the saturated zone is approximated by the local surface slope

- the decay of hydraulic conductivity $K$ with depth $z$ is an exponential function of storage deficit $S$, with $m$ being the recession parameter, written as

$$
K(z)=K_{S} e^{S / m}
$$

Other formulations of the third assumption have been investigated, such as a linear or a parabolic approach (Ambroise et al., 1996), but are not applied in this study. 


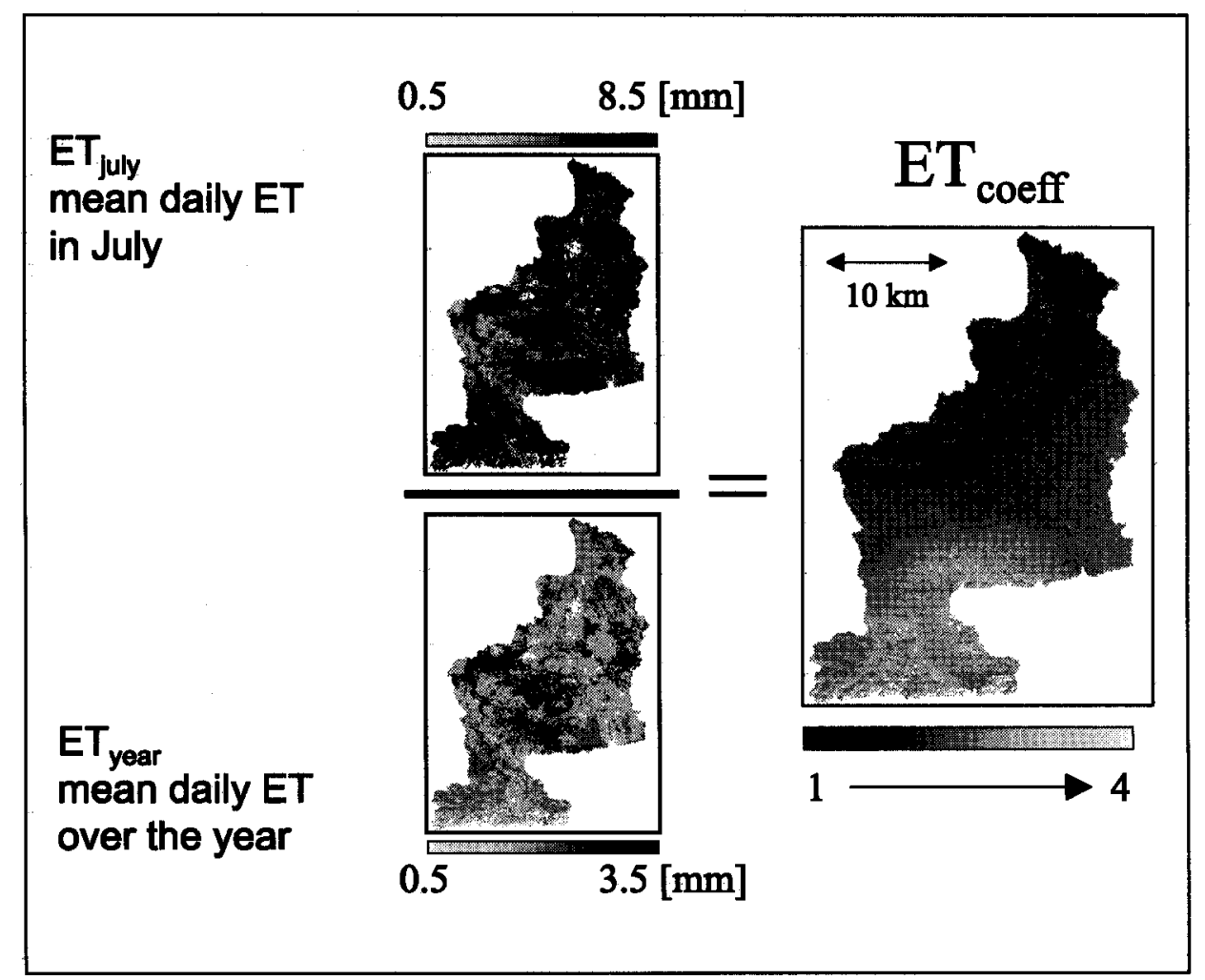

Fig. 4. Spatially distributed evapotranspiration coefficient $E T_{\text {coeff for }}$ fuly 1992.

The available spatial distribution of evapotranspiration has been incorporated into the theory of the topographic index to account for the presently underated importance of land cover and its hydrological activities in TOPMODEL. Using PROMET, the actual evapotranspiration for each pixel in the Ammer catchment is calculated on a hourly basis over the hydrological year. The monthly mean of daily evapotranspiration is evaluated and divided by the annual mean of daily evapotranspiration for each month to achieve a spatially distributed "seasonal evapotranspiration regime" for each pixel (Fig. 4).

The resulting coefficients $\left(E T_{\text {coeff }}\right)$ are used to create an evapotranspiration-soil-topographic-index $\alpha_{E T}$, considering seasonal deviations in runoff partition over the year (Eqn. 7). Thus, knowing the exact upslope area $A$ and slope $\beta$ for each pixel from the digital terrain analysis, and using the evapotranspiration coefficient and the saturated hydraulic conductivity $K_{S}$, taken from the digital soil map, an evapotranspiration-soil-topographic index $\alpha_{E T}$ for each element in the catchment can be calculated (Fig. 5). This development will consequently lead to a more dynamic description of runoff formation, allowing not only for temporal changes in the location of the variable source-areas contributing to surface runoff, but also creating an overall change in the separation of runoff components. The formerly used static distribution of index-values is replaced by a dynamic course of index distributions representing the annual course of saturation excess runoff potential in the catchment (Fig. 6). Taking into account the mean value of $\alpha_{E T}$, the shape of the $\alpha_{E T}$ is of great importance in predicting soil moisture patterns; thus longer high tails of its distribution imply a greater saturated area and hence a greater likelihood of saturation excess overland flow (Beven and Wood, 1983).

$$
\alpha_{E T}=\ln \left(\frac{A}{E T_{\text {coeff }} \cdot K_{S} \cdot \tan \beta}\right)
$$

The spatial and temporal heterogeneity of the newly derived index is demonstrated in Fig. 7, showing the actual change of $\alpha_{E T}$ over the year distinguishing selected land cover types. It must be emphasized that the $\alpha_{E T}$ is not only a land use dependent coefficient, but can be interpreted as an integretion over all influencing physiogeographic characteristics of any point in the catchment.

Three soil storages, a soil root zone, an unsaturated zone and a saturated zone, govern the distribution of water in the soil and therefore the partition of runoff in a surface and a subsurface component. Thus, for each raster element and timestep $t$, the water availability in the soil root zone (SRZ) can be calculated by balancing the water content at $t-1$, the system input (rain, snowmelt) and the output (evapotranspiration) from the SRZ. Since the evapotranspiration is already balanced, the parameter SRMAX, formerly used as the parameter for maximum storage in the upper soil layer 


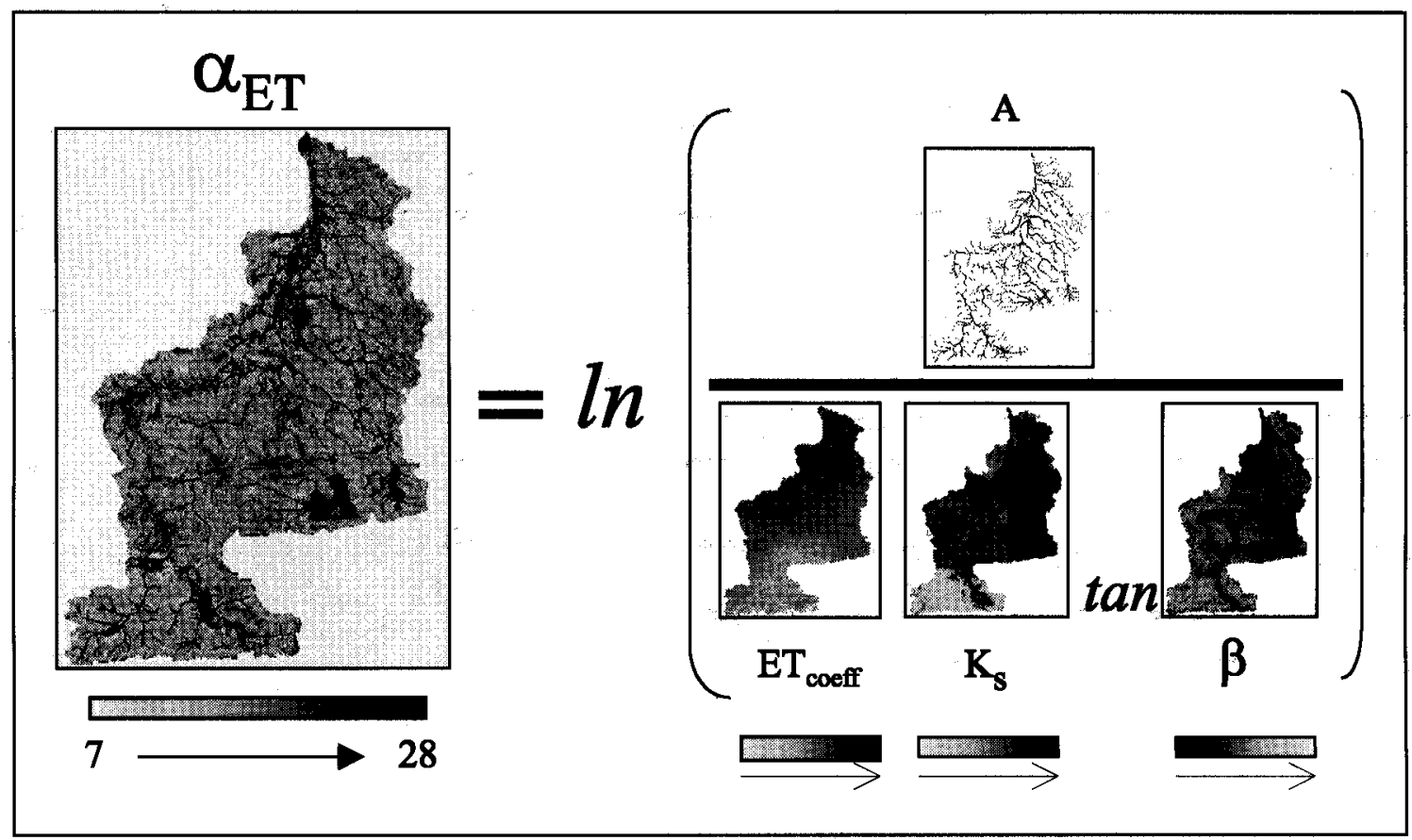

Fig. 5. Spatially distributed calculation of the $\alpha_{E T}$ within a GIS-structure.

to control the calculation of actual evapotranspiration (Bruneau et al., 1995; Beven et al., 1995) can be neglected.

Once the soil specific field capacity is reached, water is transferred from the SRZ to the unsaturated zone (SUZ), where the local storage deficit $S_{i}$ can then be computed as a function of the mean storage deficit in the catchment $S_{m}$ and the deviation of the local $\alpha_{E T}$ to its areal mean $\gamma$, scaled by the recession parameter $m$ (Eqn. 8).

$$
S_{i}=S_{m}-m\left(\ln \frac{A}{E T_{\text {coeff }} \cdot K_{S} \cdot \tan \beta_{i}}-\gamma\right)
$$

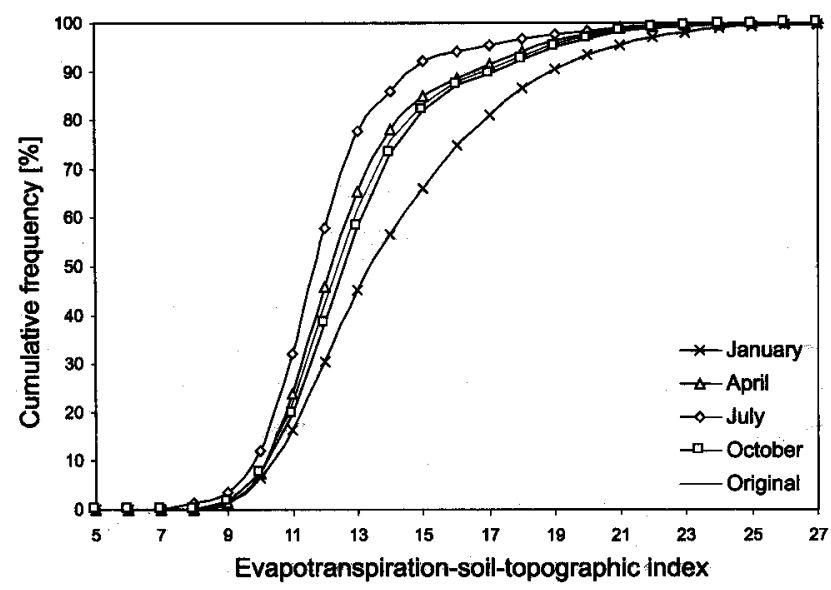

Fig. 6. Dynamic course of $\alpha_{E T}$ distributions (cumulative frequency) for the Ammer catchment.
The recharge rate $q_{v}$ into the saturated zone SZ (Beven and Wood, 1983) is furthermore calculated as

$$
q_{v}=\frac{S_{U Z}}{S_{i} \cdot t_{d}}
$$

where $S_{U Z}$ is the store of the unsaturated zone and $t_{d}$ is a soil specific time delay parameter. The baseflow volume $Q_{b}$ of each subcatchment at each timestep results as a function of integrated storage deficit $S_{m}$ (Obled et al., 1994; Beven et al., 1995), initial baseflow $\ell_{0}$, and the recession parameter $m$

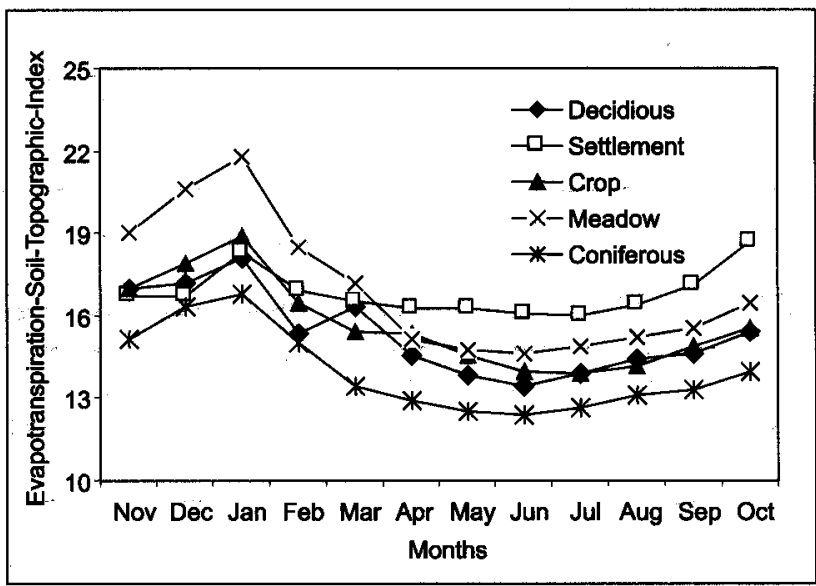

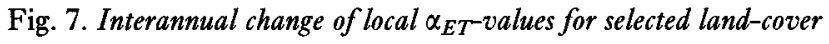
types. 


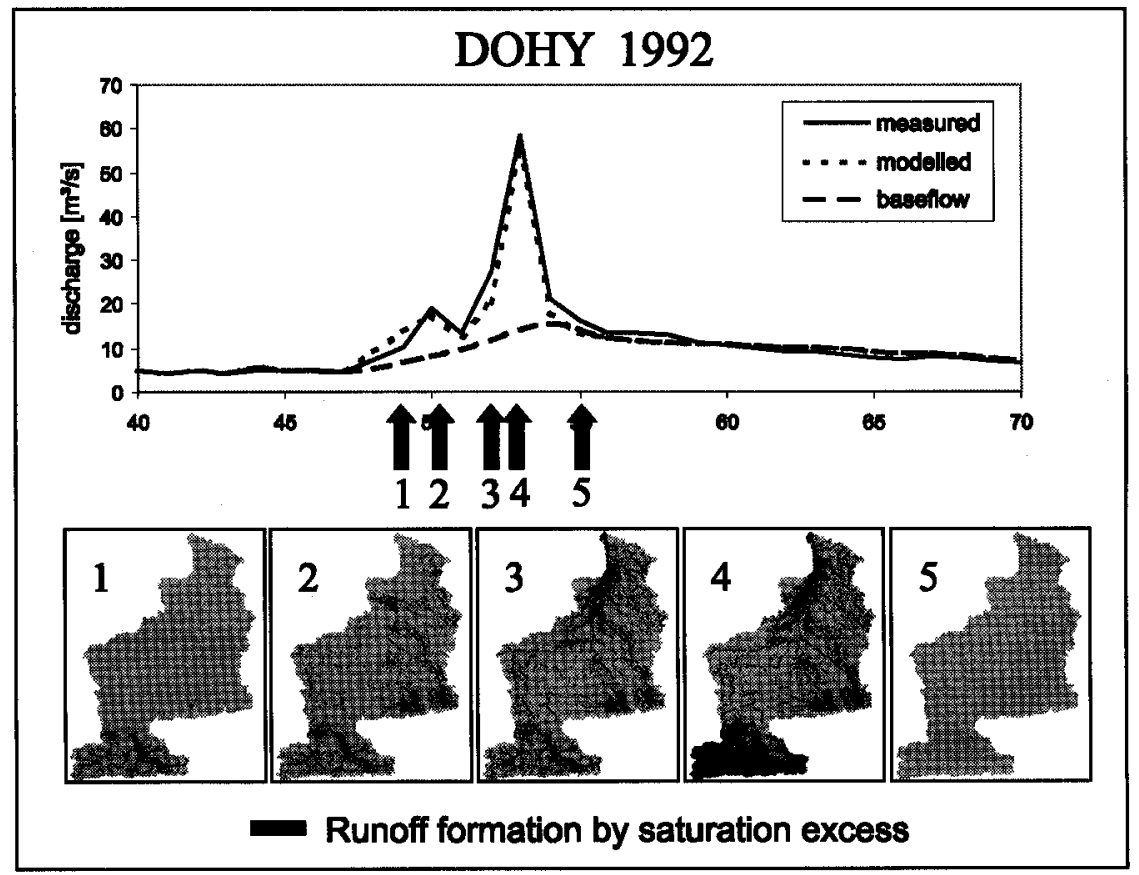

Fig. 8. Development of saturated area in the Ammer catchment during a flood event.

over the basin and can therefore be written as:.

$$
Q_{b}=Q_{0} \cdot e^{S_{m} / m}
$$

Once the local storage deficit is zero, the soil is saturated to the top and saturation excess occurs. Infiltration excess, as the second possibility of surface runoff, is calculated by the Green-Ampt infiltration model (Eqn. 11), with $f$ being the infiltration rate, the porosity $\Phi$, the effective soil suction $S_{f}$, the initial water content $\theta_{i}$ and the accumulated infiltration amount $F$.

$$
f=K\left[1+\left(\left(\Phi-\theta_{i}\right) \cdot \frac{S_{f}}{F}\right)\right]
$$

The infitration excess is thus added to the saturation excess, where it undergoes an overland flow algorithm based on the application of time-area functions, derived individually for each subcatchment from digital terrain analysis. The time of concentration $T_{c}$, and hence the overland flow velocity as its derivative, was calculated by the SCS-method (Eqn. 12, Soil Conservation Service, 1985), for which all necessary parameters were provided from the GIS (overland retention from land-cover-soil complex $S$ ) and the digital terrain analysis (hydraulic length $\lambda$ and mean catchment slope $\gamma$ ).

$$
T_{c}=\frac{1,67 \cdot \lambda^{0.8} \cdot(S-1)}{1900 \cdot \sqrt{\gamma}}
$$

The channel routing was then performed using a simple constant wave velocity routing algorithm (Beven \& Wood, 1993). The Ammer river and its tributaries are equipped overall with ten gauging stations, for which the master recession curves and thus the subcatchment specific recession parameters $m$ were derived by an analysis of numerous baseflow recession curves. The $1 / Q$ transformation of an exponential transmissivity profile (Ambroise et al., 1996) was assumed. Each ungauged subcatchment was then assigned to one of the resulting values of $m$, according to physiographic similarity. It is important to state that the soil vertical $K_{S}$ values for the lateral hydraulic conductivity remain the only model-inherent 'fitting' parameter for the description of runoff formation.

Output options include the spatial and temporal development of runoff formation in each catchment, the local storage deficit, the local computed water table depth and the saturation excess. Figure 8 shows the temporal and spatial distribution of saturation excess in the Ammer catchment with the resulting modelled hydrograph during a flood event in 1992.

\section{Results}

In a preliminary model run, using a spatially distributed but conventional soil-topographic index, the hydrograph for the hydrological year 1992 and the spatial and temporal distribution of surface runoff and storage deficit of the unsaturated soil compartment were computed on a daily basis and a $30 \mathrm{~m}$ grid. The model results show some specific deviations, which originate from neglecting seasonal dynamics. Though the runoff volume is modelled with reasonable accuracy throughout the year, the seasonally false 


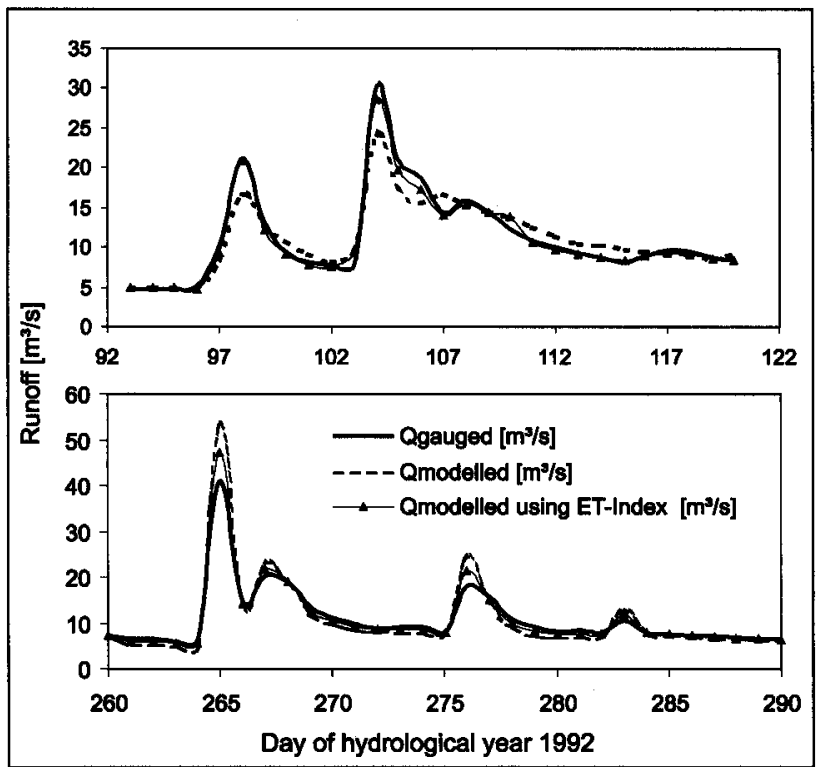

Fig. 9. Effect of using the $\alpha_{E T}$ (ET-index) in hydrograph simulations for a winter (upper) and a summer event.

partition between its components shows the need for further investigation. During the winter months, the modelled surface runoff consistently underestimates the measured values while overestimating the baseflow term; the reverse effect can be detected during the summer months. It is believed that influencing factors for this phenomenon can be seen in the seasonality of the plant root activity, its influence on evapotranspiration and hence the emptying of the uppermost soil root zone, the seasonal surface roughness and surface flow resistance and the increased re-infiltration capacity along macro-pores. It is, therefore, assumed that the potential for producing saturation excess rises in winter time, due to a reduced or non-existing root activity in the top-layer of the soil profile. The method applied to correct the resulting model errors has been described in the previous section by adopting the evapotranspiration-soiltopographic index $\alpha_{E T}$. Re-running the model shows remarkable improvements in the hydrograph simulation for selected events (Fig. 9) and in the annual comparison of differences (Fig. 10).

The redistribution of the runoff volume leads to a better simulation of the discharge peaks and to a improved approximation of the measured runoff hydrograph in general. Figure 11 shows the final model result applying the $\alpha_{E T}$ for the Ammer basin over the hydrological year 1992 with an efficiency $\epsilon$ of 0.92 (Nash and Sutcliffe, 1970).

Taking advantage of the graphical output of the PROMET infrastructure, an accumulated saturation excess image is created, displaying the frequency of saturation at each point in the catchment over the hydrological year 1992 (Fig. 12, $n=365$ ). It delineates the areas of high saturation probability and can therefore be used in a variety of

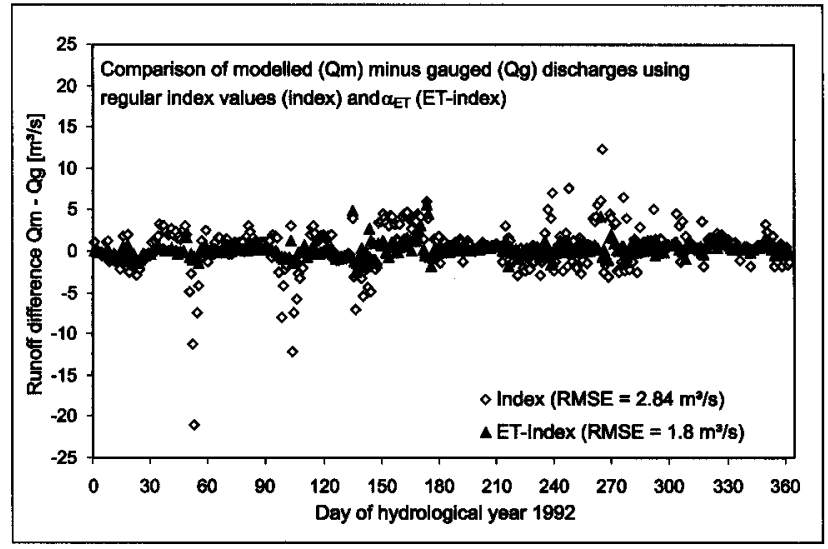

Fig. 10. Differences of modelled runoff-measured runoff before and after applying $\alpha_{E T}$.

domains, such as agriculture, to identify areas of both likely water stress or inundation.

\section{Conclusions}

The paper presents a model structure, combining the physically-based SVAT-model PROMET with an extended version of the conceptual TOPMODEL, to simulate the catchment hydrology for the Ammer basin over a one-year period. In this approach, the interpolated precipitation fields as well as the calculated snowmelt and evapotranspiration patterns provided by PROMET are evaluated as spatially distributed and high resolution terms to balance the soil water storage retrieval for the runoff component in a distributed sense. The runoff model introduces the application of a dynamic evapotranspiration-soil-topographic index $\alpha_{\mathrm{ET}}$, to account for an annual course in runoff formation controlled by plant development. For this

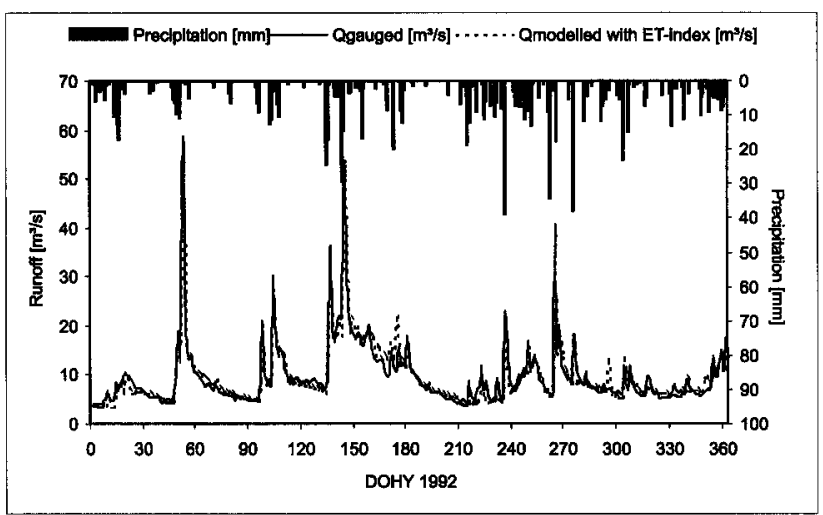

Fig. 11. Final model result for the hydrological year 1992 in the Ammer basin using $\alpha_{E T}(\varepsilon=0.92)$. 


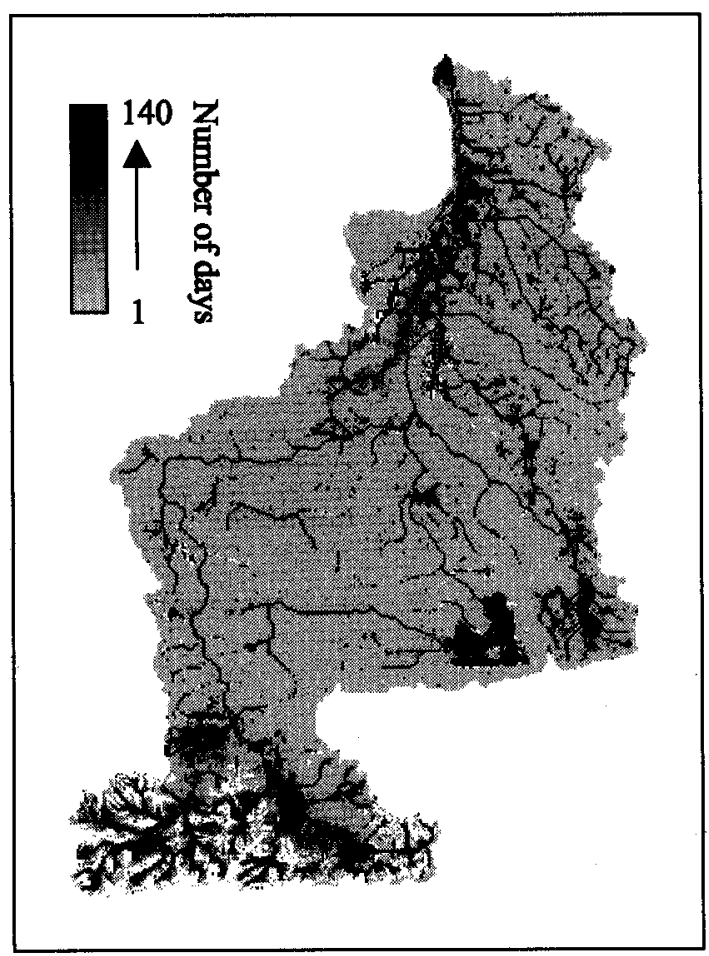

Fig. 12. Frequency map of saturation excess (number of days) in the Ammer catchment for 1992.

purpose, a distributed evapotranspiration coefficient is calculated from the validated PROMET results of a 14-year time period. In contrast to most existing TOPMODEL applications, where runoff formation is basically controlled in time and space by a static distribution function, this enhancement accounts for seasonal dynamics in runoff formation as a function of plant development and therefore allows a more realistic description of variability in the variable source-area concept. For the Ammer test site, the application of this newly implemented index formulation leads to a considerable improvement in the simulation result, quantified by a decrease of the root mean square error from 2.7 to $1.8 \mathrm{~m}^{3} \mathrm{~s}^{-1}$ over the model period. This approach provides a simple but efficient method to include the influence of vegetation in modelling runoff formation. The example given provides a first step towards the quantitative assessment of distribution and dynamics of land surface parameters in a conceptual rainfall-runoff model, provided by an uncalibrated physically-based SVAT model. Applying the evapotranspiration coefficient in the formulation of the topographic index theory serves as a useful tool accounting for changes in runoff production and formation in terms of a rapidly changing environment. The approach presented here allows for a reduction in calibration. Further testing and sensitivity analysis will be necessary to establish the $\alpha_{E T}$ for a wider range of applications and before the important scale issue can be investigated.

\section{Acknowledgements}

This work has been funded by the German Research Association (DFG). The contribution of data and gauging equipment by the Bavarian Water Authority and the German Weather Service (DWD) is gratefully acknowledged. Dr. J. Garbrecht from the Grazinglands Research Institute, USDA, is thanked for providing the TOPAZ software. Special thanks go to Prof. Dr. Keith Beven for sharing his expertise and distributing the basic TOPMODEL codes.

\section{References}

Abbott, M.B., Bathurst, J.C., Cunge, J.A. and O'Connell, P.E., 1986. An Introduction to the European Hydrological SystemSystem Hydrologique Europeen "SHE". f. Hydrol. 87, 45-59, $61-77$.

Ambroise, B, Beven, K.J. and Freer, J., 1996. Towards a generalisation of the TOPMODEL concepts: topographic indices of hydrological similarity. Water Resour. Res. 32, 2135 2145.

Baldocchi, D.D., Hicks, B.B. and Camara, P., 1987. A canopy stomatal resistance model for gaseous depositions to vegetated surfaces. In: Atm. Environ. 21, 91-101.

Beven, K.J. and Kirkby, M.J., 1979. A physically based variable contributing area model of basin hydrology. Hydrol. Sci. Bull., 24, 43-69.

Beven, K.J., 1993. Prophecy, reality and uncertainty in distributed hydrological modelling. Advan. Water Resour. 16, 41-51.

Beven, K.J., (Ed.), 1997. Distributed Modelling in Hydrology: Applications of TOPMODEL, Wiley, Chichester, UK.

Beven, K.J., Lamb, R., Quinn, P.F., Romanowicz, R. and Freer, J., 1995. TOPMODEL, in: Computer Models of Watershed Hydrology V.P. Singh (Ed). Water Resources Publications, 627-668.

Beven, K.J., Quinn P., Romanowicz, R., Freer, J., Fisher, J. and Lamb, R., 1994. TOPMODEL and GRIDATB: A users guide to the distribution versions. CRES Technical Report TR110 (2 ${ }^{\text {nd }}$ Ed.), Lancaster University, Lancaster.

Beven, K.J. and Wood, E.F., 1983. Catchment geomorphology and the dynamics of runoff contributing areas. 7. Hydrol., 65, 139158.

Beven, K.J. and Wood, E.F., 1993. Flow routing and the hydrological response of channel networks. Channel Network Hydrology Beven \& Kirkby (Eds). Wiley, Chichester, Chapter 5.

Bonham-Carter, G., 1994. Geographic Information Systems for Geoscientists: Modelling with GIS. Kidlington, Elsevier Science, $392 \mathrm{~S}$.

Braden, H., 1995. The Model AMBETI, A Detailed Description of a Soil-Plant-Atmosphere Model. Berichte des Deutschen Wetterdienstes, Nr.195, Offenbach am Main.

Brooks, R.H. and Corey, A.T., 1964. Properties of Porous Media Affecting Fluid Flow. F. Irr. Drain. Div., Amer. Soc. Civ. Engin. IR2, 61-88.

Bruneau, P., Gascuel-Odoux, C., Robin, P., Merot, Ph. and Beven, K.J., 1995. The sensitivity to space and time resolution of a hydrological model using digital elevation data. Hydrol. Process., 9, 69-81.

Eagleson, P.S., 1978. Climate, Soil and Vegetation, 1-7. Water Resour. Res., 14, 705-776.

Famiglietti, J. and Wood, E.F., 1994. Multiscale modelling of spatially variable water and energy balance processes. Water Resour. Res., 30, 3061-3078.

Franchini, M., Wendling, J., Obled, C. and Todini, E., 1996. Physical interpretation and sesitivity analysis of the TOPMODEL. 7. Hydrol., 175, 293-338.

Garbrecht, J. and Martz, L., 1995. TOPAZ-Version 1.1. National 
Agricultural Water Quality Laboratory, USDA, Agricultural Research Service, Durant (Oklahoma).

Kovar, K. and Nachtnebel, H.P. (Editors), 1996. HydroGIS'96: Application of Geographic Information Systems in Hydrology and Water Resources Management., Proceedings of the Vienna Conference. IAHS. No. 235.

Lu Zhang, 1995. A one-layer resistance model for estimating regional evapotranspiration using remote sensing data. Agric. Forest Meteorol., 77, 241-261.

Mauser W. and Schadlich S., 1998. Modelling the patial distribution of evapotranspiration using remote sensing data and PROMET. 7. Hydrol., 213, 250-267.

Möser, W. and Raschke, E., 1983. Mapping of Global radiation and of Cloudiness from METEOSAT image data. Meteorologische Rundschau 36.

Monteith, J.L., 1978. Evaporation and the environment. Symp. Soc. Expl. Biol. 19, 205-234.

Moore, I.D., Gallant, J.C., Guerra, L. and Kalma, J.D., 1993. Modelling the spatial variability of hydrological processes using Geographical Information Systems, in HydroGIS 93: Application of Geographical Information Systems in Hydrology and Water Resources, K Kovar and H.P. Nachtnebel (Eds). IAHS Pubn. No. 211, 161-169.

Nash, J.E. and Sutcliffe, J.V., 1970. River flow forecasting through conceptual models, partl-a discussion of principles. F. Hydrol. $10,282-290$

Norman, JM., 1979. Modelling the complete plant canopy. Modification of the Areal Environment of Plants. Amer. Soc. Agric. Engr. St. Foseph, 249-277.

Obled, Ch., Wendling, J. and Beven, K.J., 1994. The sensitivity of hydrological models to spatial rainfall patterns: an evaluation using observed data. 7. Hydrol., 159, 305-333.

Quinn, P.F., Beven, K.J. and Culf, A., 1995. The introduction of macroscale hydrological complexity into land surface-atmo- sphere transfer function models and the effect on planetary boundary layer development. F. Hydrol., 166, 421-444.

Romanowicz, R., Beven, K.J. and Moore, R.V., 1993. GIS and distributed hydrological models, in Geographical Information Handling-Research and Applications, P.M. Mather (Ed.). Wiley, Chichester, 197-205.

Saulnier, G-M., Beven, K.J. and Obled, Ch., 1998. Including spatially variable soil depths in TOPMODEL. F. Hydrol., 202, 158-172.

Schulla, J., 1997. Hydrologische Modellierung von Fluß gebieten zur Abschätzung der Folgen von Klimaänderungen. Züricher Geographische Schriften, H. 69, 161 S., Zürich.

Seibert, J., 1999. Conceptual Runoff Models-Fiction or Representation of Reality? Comprehensive Summaries of Uppsala Dissrtations from the Faculty of Science and Technology 436. Acta Universitatis Upsaliensis.

Soil Conservation Service (Ed.), 1985. Hydrology. Engineering Handbook, Section 4. U.S. Department of Agriculture, Washington, D.C.

Stolz, R. and Mauser W., 1996. A fuzzy approach for improving landcover classifications by integrating remote sensing and GIS data. Progress in Environmental Remote Sensing Research and Applications. Parlow (ed.): Balkema, Rotterdam, 33-41.

Todini, E., 1996. The ARNO rainfall-runoff model. F. Hydrol., 175, 339-382.

von Hoynigen-Huene, H., 1983. Die Interzeption des Niederschlages in landwirtschaftlichen Pflanzenbeständen. Schriftenreien $D V W K$ Nr. 57, p. 153.

Watson, F.G.R., Vertessy, R.A. and Band, L.E., 1996. Distributed parameterization of a large scale water balance model for an Australian forested region. HydroGIS'96: Application of Geographic Information Systems in Hydrology and Water Resources Management., Proceedings of the Vienna Conference. IAHS. No. $235 ; 157-166$. 